\title{
Pengaruh Aktivitas Bersepeda Terhadap Peningkatan Volume Oksigen Maksimal (Vo2Max) Pada Komunitas Sepeda "PIT Merasi"
}

\section{The Effect of Cycling on Increasing the Maximum Oxygen Volume (Vo2Max) on the "PIT Merasi" Bike Community}

\author{
Yoga Nurfauzi ${ }^{1}$, Hilmainur Syampurma² \\ 1,2Prodi Pendidikan Jasmani, Kesehatan dan Rekreasi, Fakultas IImu Keolahragaan \\ Universitas Negeri Padang \\ email: yoga16nurfauzi@gmail.com¹, hilmainursyam@fik.unp.ac.id²
}

do)

: https://doi.org/10.20884/1.paju.2021.2.2.3788

\begin{abstract}
Abstrak
Masalah dalam penelitian ini yaitu rendahnya tingkat daya tahan jantung paru anggota komunitas sepeda Pit Merasi, yang disebabkan belum adanya latihan yang terprogram secara rutin. Penelitian ini bertujuan untuk mengetahui dan memaparkan pengaruh aktivitas bersepeda terhadap peningkatan $\mathrm{VO}_{2} \mathrm{Max}$ pada komunitas sepeda Pit Merasi Kabupaten Musi Rawas, Provinsi Sumatera Selatan. Metode yang digunakan dalam penelitian ini adalah Metode eksperimen semu dengan teknik penarikan sampel pada penelitian ini menggunakan total sampling yang berjumlah 20 orang. Perlakuan dalam penelitian ini berupa program latihan bersepeda selama 16 kali pertemuan dengan frekuensi 4 kali seminggu dan menggunakan MFT (Multistage Fitness Test) untuk mengetahui tingkat $\mathrm{VO}_{2} \mathrm{Max}$ pada komunitas sepeda Pit Merasi. Hasil MFT (Multistage Fitness Test) sebelum diberikan perlakuan menunjukkan bahwa nilai rata-rata sebesar 29.71, nilai standar deviasi sebesar 4.63 dengan nilai terendah sebesar 22.10 dan nilai tertinggi sebesar 36.40. Sedangkan Hasil MFT (Multistage Fitness Test) setelah diberikan perlakuan menunjukkan bahwa nilai rata-rata sebesar 33.59, nilai standar deviasi sebesar 5.06 dengan nilai terendah sebesar 24.30 dan nilai tertinggi sebesar 40.20, Hasil Uji Independent sample $t$-test didapatkan : Nilai thitung $(11.68)>t_{\text {tabel }}(1.729)$ pada taraf signifikansi $=0,05$. Maka Ha diterima dan Ho ditolak. Berdasarkan hasil uji diatas dapat disimpulkan bahwa aktivitas bersepeda meningkatkan $\mathrm{VO}_{2} \mathrm{Max}$ secara signifikan pada anggota komunitas sepeda Pit Merasi.
\end{abstract}

Kata Kunci : Bersepeda, Komunitas PIT Merasi, $\mathrm{VO}_{2} \mathrm{Max}$

\begin{abstract}
The problem in this study is the low level of cardiac and pulmonary endurance of the members of the Merasi Pit bike community, which is due to the absence of routine programmed training. This study aims to determine and describe the effect of cycling on increasing VO2Max in the Pit Merasi bicycle community, Musi Rawas Regency, South Sumatra Province. The method used in this study

Alamat Koresponden : Pendidikan Jasmani, Kesehatan dan Rekreasi, Fakultas IImu Keolahragaan Universitas Negeri Padang

Email : yoga16nurfauzi@gmail.com


is a quasi-experimental method with the sampling technique in this study using a total sample of 20 people. The treatment in this study was a cycling exercise program for 16 meetings with a frequency of 4 times a week and using the MFT (Multistage Fitness Test) to determine the VO2Max level in the Pit Merasi bicycle community. The results of the MFT (Multistage Fitness Test) before being given the treatment showed that the mean value was 29.71, the standard deviation value was 4.63 with the lowest value of 22.10 and the highest value of 36.40. $t$ table (1.729) at the significance level $=0.05$. $>$ And the MFT (Multistage Fitness Test) results after being given the treatment showed that the mean value was 33.59, the standard deviation value was 5.06 with the lowest value of 24.30 and the highest value was 40.20, the results of the Independent sample t-test were obtained: The value of tcount (11.68) So Ha was accepted and Ho was rejected. Based on the test results above, it can be concluded that cycling activity increases VO2Max significantly in members of the Pit Merasi bicycle community.

Keywords : Cycling, PIT Merasi Community, VO2Max

\section{PENDAHULUAN}

Olahraga merupakan kebutuhan hidup yang bersifat periodik, artinya olahraga sebagai alat untuk memelihara dan membina kesehatan. Olahraga merupakan alat untuk merangsang pertumbuhan dan perkembangan jasmani, rohani dan sosial. Olahraga atau aktivitas jasmani dijadikan sebagai sarana rekreasi yang dapat meningkatkan kesehatan dan kebuagaran bagi pelakunya (Dewi et al., 2020; Kasriman, 2017). Oahraga rekreasi yang sangat diminati oleh masyarakat saat ini yaitu bersepeda. Bersepeda merupakan olahraga yang sama baiknya dengan berlari dan berenang, yang bermanfaat untuk meningkatkan kebugaran (Dirgantoro, Shadiqin, \& Aisyah, 2018). Bersepeda dapat menjaga kesehatan jasmani karena dapat meningkatkan kebugaran dan kekebalan tubuh (Utomo, 2020). Hal ini juga sesuai dengan pendapat Arjuna (2012) bahwa bersepeda adalah olahraga yang murah, aman dan mempunyai banyak manfaat, seperti untuk menjaga kebugaran jasmani.

Dari beberapa pendapat di atas dapat disimpulkan bahwa bersepeda dapat berpengaruh terhadap tingkat kebugaran jasmani. Mulai dari penguatan tulang yang rawan pada tubuh, memperbaiki sirkulasi udara secara keseluruhan, metabolisme tubuh menjadi lancar dan mampu meningkatkan kekebalan tubuh. Latihan-latihan aerobik berusaha meningkatkan kapasitas kardiorespatori, karena latihan aerobik membebani sistem kardiorespatori dan bertujuan untuk menggunakan oksigen sebanyak mungkin (Chrisly, Djon, \& Shane, 2015; Purba, Widowati, \& Daya, 2020). 
Yoga Nurfauzi \& Hilmainur Syampurma | Pengaruh Aktivitas Bersepeda Terhadap Peningkatan Volume Oksigen Maksimal (Vo2Max) Pada Komunitas Sepeda "PIT Merasi"

Latihan aerobik memerlukan pasokan oksigen yang cukup untuk dapat melakukan aktivitas dalam waktu yang lama. Oksigen merupakan salah satu bahan yang dibutuhkan manusia dan salah satu komponen yang dibutuhkan otot untuk beraktifitas berat atau ringan (Septian, Lazoardy Zola, Jatmiko, 2018). Oleh karena itu, pernapasan dan detak jantung akan meningkat selama aktivitas aerobik. Adapun berbagai kegiatan yang masuk dalam latihan aerobik yaitu senam aerobik, jalan cepat, jogging, berenang, berlari, bersepeda dan zumba. Dari berbagai jenis olahraga, bersepeda merupakan salah satu olahraga aerobik yang cukup efektif untuk meningkatkan $\mathrm{VO}_{2} \mathrm{Max}$. Volume oksigen maksimal adalah kemampuan jantung-paru dan sel-sel untuk bekerja dengan optimal dalam kondisi rehat maupun pada saat beraktivitas untuk menerima oksigen lalu mengalirkannya ke membran yang aktif untuk metabolise tubuh (Febi, 2020).

$\mathrm{VO}_{2} \mathrm{Max}$ adalah kemampuan seseorang untuk melakukan suatu aktivitas dalam waktu tertentu tanpa mengalami kelelahan yang berarti, dan orang tersebut masih mempunyai cadangan tenaga untuk melakukan suatu aktivitas (Juniardi, Atiq, \& Purnomo, 2016). Ada beberapa hal yang harus di perhatikan untuk melatih $\mathrm{VO}_{2} \mathrm{Max}$, yaitu, latihan harus menggunakan otot-otot besar secara intensif dalam durasi yang cukup lama (Rustiawan, 2020). Beberapa Faktor yang mempengaruhi nilai $\mathrm{VO}_{2} \mathrm{Max}$ antara lain, jenis kelamin, suhu dan keadaan latihan (Juniardi et al., 2016). $\mathrm{VO}_{2} \mathrm{Max}$ dalam olahraga merupakan suatu hal yang sangat penting. Oksigen dibutuhkan untuk membantu dalam proses metabolisme tubuh. Pengukuran $\mathrm{VO}_{2} \mathrm{Max}$ dapat dengan alat maupun dengan tes. Salah satu tes yang bisa di gunakan adalah MFT (Multi fitness test). MFT yaitu lari multi tahap atau biasa disebut dengan Bleep test. $\mathrm{VO}_{2} \mathrm{Max}$ diukur berdasarkan jumlah tahapan yang mampu diperoleh, kemudian dikonversikan ke dalam norma yang telah di tentukan.

Bersepeda tumbuh menjadi hobi yang sangat popular dan menjawab kebutuhan berbagai lapisan umur dan merambah ke berbagai macam strata ekonomi. Pit Merasi merupakan salah satu komunitas bersepeda yang sering mengikuti event-event fun bike. Namun pada saat mengikuti event fun bike Musi Rawas sehat pada tanggal 14 Juni 2020 dengan jarak tempuh sejauh $27.5 \mathrm{~km}$, diperoleh hasil bahwa anggota komunitas sepeda Pit Merasi, masih banyak yang mengalami kelelahan sebelum mencapai tujuan, seperti berhenti dan tidak mampu untuk melanjutkan bersepeda kembali. Hal tersebut terjadi karena kemungkinan disebabkan oleh tingkat $\mathrm{VO}_{2} \mathrm{Max}$ masih lemah dan beberapa anggota komunitas sepeda Pit Merasi belum melakukan latihan yang terprogram secara rutin. 
Berdasarkan data di atas menunjukkan bahwa perlu adanya usaha meningkatkan kemampuan $\mathrm{VO}_{2} \mathrm{Max}$ pada anggota komunitas sepeda Pit Merasi. Tujuan dari penelitian ini yaitu untuk mengetahui pengaruh program latihan bersepeda dengan peningkatan $\mathrm{VO}_{2}$ Max pada komunitas Pit Merasi.

\section{METODE}

Metode yang digunakan dalam penelitian ini adalah metode eksperimen semu dengan teknik penarikan sampel (Sugiyono, 2016). Penelitian ini menggunakan total sampel yang berjumlah 20 orang. Perlakuan dalam penelitian ini berupa program latihan bersepeda selama 16 kali pertemuan dengan frekuensi 4 kali seminggu. Istrumen penelitian menggunakan tes MFT (Multistage Fitness Test) yang diadopsi dari (Nurhasan dan Chalil, 2007) untuk mengetahui tingkat $\mathrm{VO}_{2} \mathrm{Max}$ pada komunitas sepeda Pit Merasi.

Penelitian ini dilaksanakan pada komunitas sepeda Pit Merasi yang berada di desa P1. Mardiharjo, Kecamatan Purwodadi, Kabupaten Musi Rawas, Provinsi Sumatera Selatan. Penelitian dilaksanakan pada bulan November-Desember 2020. Pendeskripsian data dan pengujian hipotesis dalam penelitian ini diolah dengan menggunakan statistik deskriptif dan infensial dengan Uji Independent sample t-test.

\section{HASIL}

Deskripsi data penelitian ini ditujukan untuk memberikan gambaran mengenai variabel atau sampel yang diteliti. Dalam hal ini mengenai pengaruh latihan aktivitas bersepeda terhadap peningkatan $\mathrm{VO}_{2} \mathrm{Max}$ anggota komunitas sepeda Pit Merasi Kabupaten Musi Rawas, Provinsi Sumatera Selatan. Untuk lebih jelasnya hasil pengolahan data penelitian tertera paa tabel 1. Berikut ini.

Tabel 1. Rangkuman hasil data statistik deskripsi

\begin{tabular}{llllll}
\hline Variabel & N & Minimum & Maximum & Mean & Std. Deviation \\
\hline Tes Awal $\mathrm{VO}_{2}$ Max & 20 & 22.10 & 36.40 & 29.71 & 4.63 \\
\hline Tes Akhir $\mathrm{VO}_{2}$ Max & 20 & 24.30 & 40.20 & 33.59 & 5.06 \\
\hline
\end{tabular}

Sampel yang di gunakan dalam penelitian ini yaitu anggota komunitas sepeda Pit Merasi pada kelompok umur yang sama yaitu dalam rentang usia 20 - 29 Tahun dengan jumlah 20 orang. Setelah dilakukan analisis data terhadap hasil penelitian dengan 
Yoga Nurfauzi \& Hilmainur Syampurma | Pengaruh Aktivitas Bersepeda Terhadap Peningkatan Volume Oksigen Maksimal (Vo2Max) Pada Komunitas Sepeda "PIT Merasi"

menggunakan uji- $t$ test ditemukan thitung $=11,68>t_{\text {tabel }}=1,729$ pada taraf signifikansi 0,05 . Maka Ha diterima dan Ho ditolak. Berdasarkan hasil pengujian hipotesis membuktikan bahwa latihan bersepeda dapat memberikan pengaruh secara signifikan terhadap peningkatan $\mathrm{VO}_{2} \mathrm{Max}$ anggota komunitas sepeda Pit Merasi, Kabupaten Musi Rawas.

\section{PEMBAHASAN}

Bersepeda merupakan olahraga yang sama baiknya dengan berlari dan berenang, yang bermanfaat untuk meningkatkan kebugaran (Dirgantoro et al., 2018). Bersepeda dapat menjaga kesehatan jasmani karena dapat meningkatkan kebugaran dan kebalan tubuh. (Utomo, 2020). Hal ini juga senada dengan pendapat (Arjuna, 2012) bahwa Bersepeda adalah olahraga yang murah, aman dan mempunyai banyak manfaat, seperti untuk menjaga kebugaran jasmani.

Dari beberapa pendapat di atas dapat disimpulkan bahwa bersepeda dapat berpengaruh terhadap tingkat kebugaran jasmani. Bersepeda secara terprogram mampu meningkatkan kebugaran pada setiap komunitas bersepeda (Hadi, 2020). Latihan-latihan aerobik berusaha meningkatkan kapasitas kardiorespatori, karena latihan aerobik membebani sistem kardiorespatori dan bertujuan untuk menggunakan oksigen sebanyak mungkin (Qohhar, 2017; Sastaman, 2015).

Latihan adalah proses melakukan kegiatan yang telah terkonsep dan memiliki tujuan yang jelas sehingga akan terciptanya tujuan yang diharapkan (Wardani, 2020). Selanjutnya Latihan adalah proses melakukan kegiatan olahraga yang telah direncanakan secara sistematis dan terstruktur dalam jangka waktu yang lama untuk meningkatkan kemampuan gerak baik dari segi fisik, teknik, taktik, dan mental untuk menunjang keberhasilan siswa atau atlet dalam memperoleh prestasi olahraga yang maksimal (Langga \& Supriyadi, 2016).

Hasil dari penelitian ini adalah adanya peningkatan yang signifikan karena program latihan yang diberikan mampu memberikan pengaruh terhadap $\mathrm{VO}_{2} \mathrm{Max}$ anggota komunitas sepeda Pit Merasi Kabupaten Musi Rawas. Pelaksanaan peroram latihan yang tepat dan sesuai dengan kapasitas tubuh dapat memberi efek positif dalam meningkatkan kondisi fisik, khususnya kapasitas daya tahan jantung dan paru $\left(\mathrm{VO}_{2} \mathrm{Max}\right)$. 


\section{SIMPULAN}

Berdasarkan hasil analisis data dan pengujian hipotesis dapat di simpulkan bahwa aktivitas bersepeda dapat meningkatan $\mathrm{VO}_{2} \mathrm{Max}$ anggota komunitas sepeda Pit Merasi Kabupaten Musi Rawas. Berdasarkan kesimpulan yang telah dikemukakan diatas, maka peneliti mengajukan beberapa saran sebagai berikut :Anggota komunitas sepeda Pit Merasi Kabupaten Musi Rawas, agar dapat melakukan aktivitas sepeda secara terprogram sehingga dapat menjaga dan meningkatkan $\mathrm{VO}_{2} \mathrm{Max}$. Peneliti selanjutnya dapat meneliti dengan jumlah sampel yang lebih banyak, komponen kondisi fisik yang berbeda dan penelitian juga dapat dilakukan kepada komunitas berbeda selain olahraga bersepeda.

\section{REFERENSI}

Arjuna, F. (2012). Menjaga Kebugaran Jasmani Dengan Bersepeda. Pendidikan Kesehatan Dan Rekreasi FIK -UNY. 1-25.

Candra Dewi, N. K. A. T., Astra, I. K. B., \& Suwiwa, I. G. (2020). Motivasi Mahasiswa Prodi Pendidikan Jasmani Kesehatan Dan Rekreasi Fakultas Olahraga Dan Kesehatan Menjaga Kebugaran Jasmani Pada Masa Pandemi Covid-19. Jurnal IImu Keolahragaan Undiksha. https://doi.org/10.23887/jiku.v8i1.29573

Chrisly M., P., Djon, W., \& Shane H. R., T. (2015). Manfaat Latihan Olahraga Aerobik Terhadap Kebugaran Fisik Manusia. Jurnal E-Biomedik.

Dirgantoro, E. W., Shadiqin, A., \& Aisyah, S. (2018). Pengaruh Bike Interval Training Terhadap Peningkatan Daya Tahan Jantung Paru Anggota Club Cycle Bajai. Multilateral Jurnal Pendidikan Jasmani Dan Olahraga, 17(1), 13-17. https://doi.org/10.20527/multilateral.v17i1.5016

Hadi, F. K. (2020). Aktivitas Olahraga Bersepeda Masyarakat Di Kabupaten Malang Pada Masa Pandemi Covid-19. Sport Science and Education Journal. https://doi.org/10.33365/ssej.v1i2.777

Juniardi, E., Atiq, A., \& Purnomo, E. (2016). Survei Tingkat Volume Oksigen Maksimal (vo 2 max) Ekstrakurikuler Sepak Bola SMP 4 Sei. Nyirih. Jurnal Pendidikan Dan Pembelajaran Khatulistiwa, 5(2), 1-10.

Kasriman. (2017). Motivasi Masyarakat Melakukan Olahraga Rekreasi. Jurnal Pendidikan Jasmani Dan Olahraga.

Langga, Z. A., \& Supriyadi. (2016). Pengaruh Model Latihan Menggunakan Metode Praktik Distribusi Terhadap Keterampilan Dribble Anggota Ekstrakurikuler Bolabasket SMPN 18 Malang. Jurnal Kepelatihan Olahraga, 1(1), 90-104. 
Yoga Nurfauzi \& Hilmainur Syampurma | Pengaruh Aktivitas Bersepeda Terhadap Peningkatan Volume

Oksigen Maksimal (Vo2Max) Pada Komunitas Sepeda "PIT Merasi"

Nurhasan dan Hasanudin Chalil. (2007). Tes dan Pengukuran Keolahragaan. Bandung: FPOK Universitas Pendidikan Indonesia.

Purba, J., Widowati, A., \& Daya, W. J. (2020). Peningkatan Kebugaran Jasmani Melalui Variasi Latihan Sirkuit dan Olahraga Aerobik. Jurnal IImu Keolahragaan.

Qohhar, W. (2017). Impacts of School to School to the Prosperity of Students in Serang City Senior High School. Jurnal Kependidikan Jasmani Dan Olahraga, 1(1), 43-49.

Rustiawan, H. (2020). Pengaruh Latihan Interval Training Dengan Running Circuit Terhadap Peningkatan Vo2Max. Jurnal Wahana Pendidikan, 7(1), 15. https://doi.org/10.25157/wa.v7i1.3108

Sastaman, P. (2015). Analisis Tingkat Kebugaran Jasmani Antara Siswa Yang Berjalan Kaki dan Bersepeda Pada Siswa Putra Kelas Viii Madrasah Tsanawiyah Negeri 1 Pontianak. Jurnal Pendidikan Olahraga.

Septian, Lazoardy Zola, Jatmiko, T. (2018). Pengaruh interval training terhadap vo2max atlet ukm gulat universitas negeri surabaya lazoardy zola septian. Jurnal Prestasi Olahraga, 3(1), 1-18.

Sugiyono, P. D. (2016). metode penelitian kuantitatif, kualitatif,dan R\&D. In Alfabeta, CV. Bandung: Alfabeta.

Utomo, A. W. (2020). Upaya bersepeda sebagai moda transportasi serta gaya hidup baru menjaga kebugaran jasmani. Prosiding SENFIKS (Seminar Nasional Fakultas IImu Kesehatan Dan Sains), 1(1), 118-126.

Wardani, D., \& Nurudin, A. (2020). Pengaruh Senam Bugar Muhammadiyah Terhadap Kebugaran Jasmani Siswa SMP. Physical Activity Journal (PAJU), 2(1), 100-108. doi:10.20884/1.paju.2020.2.1.3330

Yola Febi, M. S. R. (2020). Pengaruh Latihan Circuit Training Terhadap Volume Oksigen Maksimal (Vo2max) Pemain Sekolah Sepak Bola (SSB). Jurnal Stamina, 3(6), 345351. 